\title{
Analysis of Energy Consumption in Ad-Hoc on Demand Distance Vector (AODV) Protocol
}

\author{
K. Subramanian, PhD \\ Assistant Professor, \\ $P G$ and Research \\ Department of Computer Science, \\ H.H.The Rajah's College, \\ Madurai Road, \\ Pudukkottai - 622001.
}

\author{
R. Gnanakumaran \\ Research Scholar, \\ J.J College of Arts and Science, \\ Pudukkottai
}

\begin{abstract}
In Mobile Ad-Hoc Networks (MANETs), mobile devices are equipped with power (energy). In order to utilize this energy equipped devices efficiently for transmission of data packets, many energy aware routing strategies are followed. As a key note to these routing strategies, the energy aware performance metrics are analyzed reactive routing protocol Ad-Hoc on Demand Distance Vector Protocol (AODV). The comparison results prove that AODV protocol can be adopted for any routing strategy, in order to increase the performance of the network lifetime in comparison.
\end{abstract}

\section{Keywords}

Mobile Ad-Hoc Network, MANET Routing Protocols, AODV.

\section{INTRODUCTION}

Mobile Ad-Hoc networks (MANETS) are self-configured and infrastructure less network with more number of mobile devices connected via a wireless links. Energy conservation in ad-hoc networks is very important due to the limited energy availability in each wireless node [7]. Since the communication between two wireless nodes consumes more energy, it is important to minimize the cost of energy required for communication by exercising an energy aware routing strategy. Such routing procedures/policies potentially increase the lifetime of the network. In this paper, the energy metrics of AODV is compared by simulating with increasing the density of nodes.

\section{MANET ROUTING PROTOCOLS}

Routing protocols is a standard that controls how nodes decide to route the packets between the source and the destination node. Each node learns about nodes nearby and how to reach them. The routing protocols find a route for packet transmission and will transfer the packet from source to destination. The routing protocols are mainly classified in two ways.1.Table Driven protocols or proactive protocols 2.On-Demand protocols or reactive protocols. Table-driven routing protocols are trying to maintain consistent, routing information from each node to every other node in the network [2]. Each node is maintaining one or more tables that containing routing information about every other node in the network. Examples for table driven protocols are: Destination Sequenced Distance Vector Routing Protocol (DSDV), Wireless Routing Protocol (WRP), and Cluster Switch Gateway Routing (CGSR) [2]. The On-Demand protocols will establish the route between the nodes that they want to communicate. When a source node requires a route to destination node, it initiates a route discovery process in the network. This process is completed once a route is found or all possible route permutations have been examined [2]. The route remains valid until the route is no longer needed. Examples of On-Demand routing Protocols are Relative Distance Microdiversity Routing (RDMR), Temporally Ordered Routing Algorithm (TORA), Dynamic Source Routing (DSR), Ad-Hoc On Demand Distance Vector Protocol (AODV) [2].

\section{AODV}

The Ad-Hoc On-Demand Distance Vector routing protocol is a reactive routing protocol. AODV protocol is a combination of Dynamic Source Routing (DSR) and DSDV protocol [5]. It is a distance vector routing protocol and is capable of both unicast and multicast routing [8]. It will maintain the routes only between the nodes which need to communicate. The routing information will be maintained as routing tables in each node. A routing table entry expires if it has not been used or reactivated for pre-specified expiration time. When a source node wants to send the packet to a destination node then the entries in the routing table will check whether there is a current route to the destination node or not, if there is a route then the packets will transmit to destination node in that path [2]. If don't have any valid route, then the route discovery process will be initiated. For route discovery AODV is using Routing Request (RREQ), Routing Reply (RREP) Packets [1]. The RREQ packet containing the source node IP address, source node current sequence number, the destination node sequence number and broadcast ID [1][8]. The advantage of AODV is that it creates no extra traffic for communication along the existing link but requires more time to establish a connection. It is simple and doesn't require much memory or calculation.

\section{SIMULATION MODEL}

A discrete event Omnetpp 4.3 was used for the simulation purpose [6].

Table 1. Simulation Perameters

\begin{tabular}{|l|l|}
\hline Channel type & WirelessChannel \\
\hline Radio-propagation Model & TwoRayGround \\
\hline Antenna type & OmniAntenna \\
\hline Interface queue type & Drop Tail /PriQueue \\
\hline Maximum packet in Queue & $\mathbf{5 0}$ \\
\hline Network interface type & Phy/WirelessPhy \\
\hline MAC type & $\mathbf{8 0 2 \_ 1 1}$ \\
\hline Topographical Area & $\mathbf{6 0 0} \times \mathbf{6 0 0} \mathbf{m}$ \\
\hline
\end{tabular}




\begin{tabular}{|l|l|}
\hline TxPower & $\mathbf{4 . 0 0 W}$ \\
\hline RxPower & $\mathbf{3 . 0 0 W}$ \\
\hline IdlePower & $\mathbf{1 . 0 W}$ \\
\hline Transition Power & $\mathbf{0 . 0 1 W}$ \\
\hline Transition Time & $\mathbf{0 . 0 0 3 s}$ \\
\hline Sleep Power & $\mathbf{0 . 0 0 4 W}$ \\
\hline Total simulation Time & $\mathbf{6 0 0} \mathbf{~ m s}$ \\
\hline Initial energy of a Node & $\mathbf{3 0 0 . 0}$ Joules \\
\hline Routing protocols & $\mathbf{A O D V}$ \\
\hline Traffic Model & $\mathbf{F T P}$ \\
\hline Packet Size & $\mathbf{1 0 2 4}$ Bytes \\
\hline Mobility Speed & $\mathbf{1 0} \mathbf{~} / \mathbf{s}$ \\
\hline
\end{tabular}

\begin{tabular}{|l|l|l|l|l|}
\hline 30 & 2026 & 2006 & 1688.3478 & 5311.6523 \\
\hline 40 & 3656 & 3647 & 724.77563 & 8275.225 \\
\hline 50 & 3212 & 3212 & 2559.7375 & 8440.263 \\
\hline
\end{tabular}

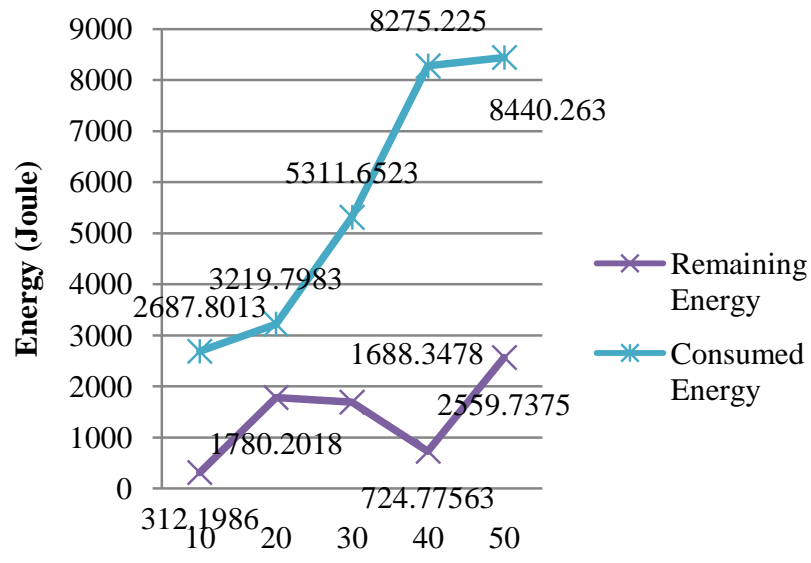

Number of Nodes

\section{Consumed Energy}

The number of nodes in the network versus the total consumed energy is considered as a metric.

\section{Remaining Energy}

The remaining energy available in each node after the transmission.

\section{Delivery Fraction [PDF]}

This is the ratio of the data packets delivered to the destination to those generated by the traffic source.

\section{Routing Overhead}

Routing overhead [9] is the number of routing packets transmitted per data packet delivered to the destination.

\section{Normalized Routing Load [NRL]}

This will be the ratio between the number of routing packets and the number of received packets. The Normalized Routing load must be low.

\section{Throughput}

It is the average rate [10] of successful message delivery over the communication channel.

\section{RESULT AND DISCUSSION}

Table 2. Energy Consumption

\begin{tabular}{|c|c|c|c|c|}
\hline $\begin{array}{l}\frac{\tilde{U}}{0} \\
\dot{0} \\
\dot{z} \\
\dot{0} \\
\dot{0} \\
\dot{z}\end{array}$ & 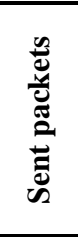 & 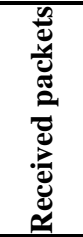 & 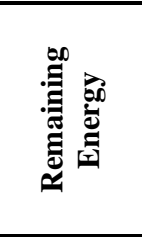 & 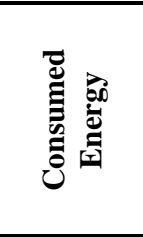 \\
\hline 10 & 1335 & 1315 & 312.1986 & 2687.8013 \\
\hline 20 & 3568 & 3552 & 1780.2018 & 3219.7983 \\
\hline
\end{tabular}




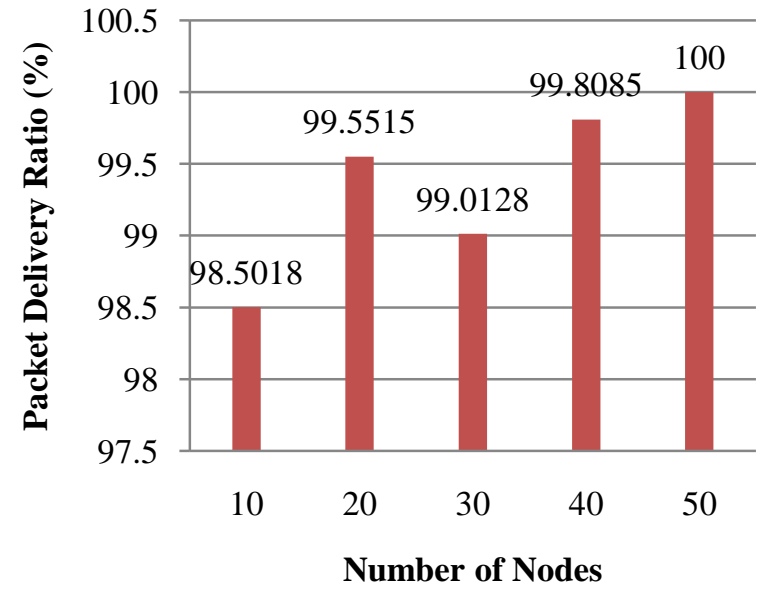

Fig 2. Packet Delevery Ratio of AODV

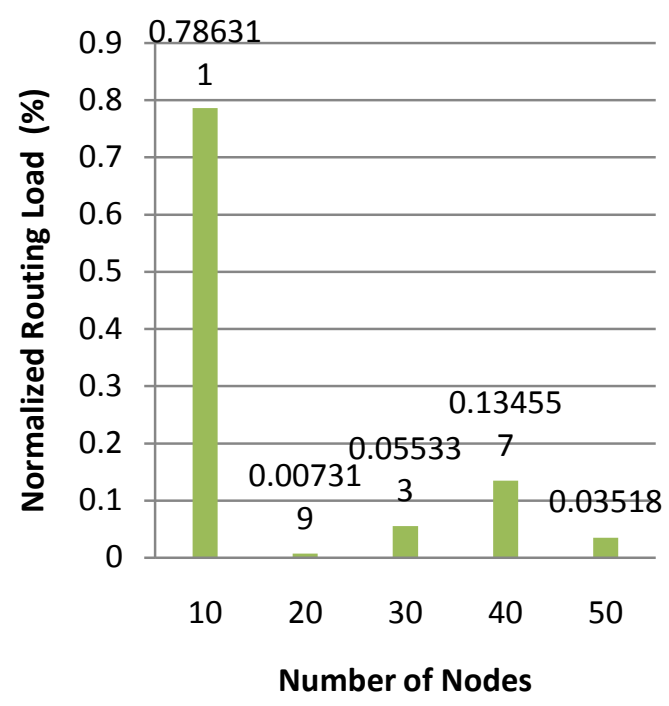

Fig 3. Normalized Routing Load of AODV

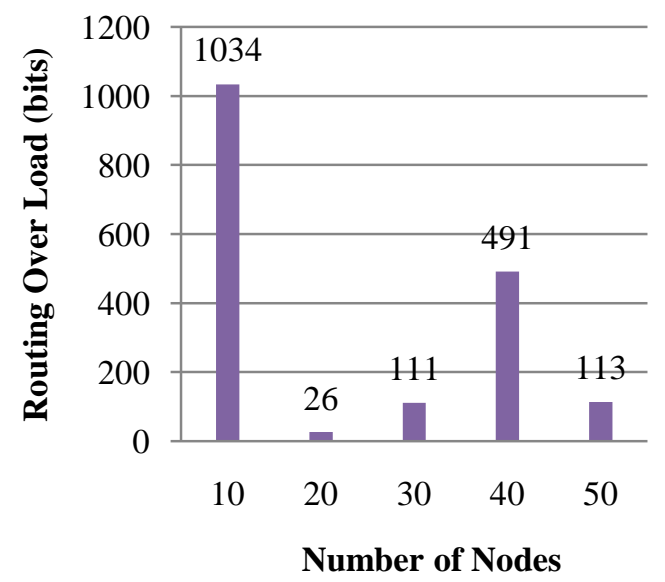

Fig 4. Routing Over Load of AODV

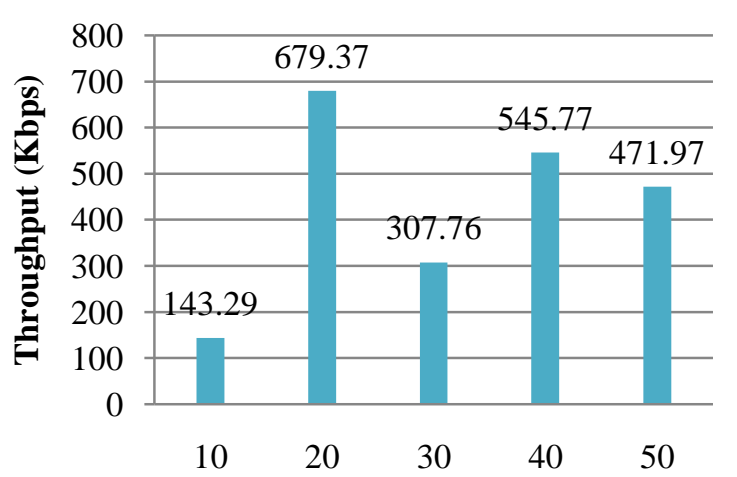

Number of Nodes

Fig 5. Throughput of AODV

\section{CONCLUSION}

The various energy-aware parameters are analyzed in Omnetpp 4.3 for AODV protocol by increasing the density of nodes. It is concluded that, AODV performs well in Packet Delivery Fraction (PDF) but in some situations due to link breakage the PDF is low. Since AODV requires less energy for transmission of packets. As the remaining energy of nodes are calculating AODV. It is advantages not to use the nodes with minimum remaining energy in order to avoid stale nodes in the network. In future the missing facility regarding energy saving technique in AODV has to overcome.

\section{REFERENCES}

[1] Manesh P. Patil, " A New Approach of Secure Power Aware Routing for Mobile Ad-Hoc Network", International Journal of Computer Applications ISSN.0975 - 8887, Volume 67- No.3, April 2013, pp 24-34

[2] Radha Rani Gupta, Mahendra Ku. Mishra and Manish Shrivastava "Power Saving Routing Protocol for Ad hoc Networks based on AODV", International Journal of Computer Applications , ISSN:0975 - 8887, Volume 85 - No 19, January 2014,pp 18-23.

[3] Manish Sharma and Laxmi Shrivastava, "Performance Evaluation of AODV and DSR on the Basis of Different Transmission Powers", International Journal of Signal Processing, Image Processing and Pattern Recognition, ISSN: 2005-4254, Vol.9, No.1 (2016), pp.275-280.

[4] Abdelwadood Mesleh, Nawal Al-Zabin,Jihad AbdelJalil, Hala Abu-Asbeh, Nesreen Al-Mutlaq, Heba AbuMatter and Maha Al-Hunati, "AODV and DSR energyaware routing algorithms: a comparative study", IJCSI International Journal of Computer Science Issues, ISSN (Online): 1694-0814, Vol. 9, Issue 6, No 1, November 2012, pp 266-271.

[5] Payel Ray, Ranjan Kumar Mondal and Debabrata Sarddar, " Design of Power Aware AODV Routing Protocol", International Research Journal of Engineering and Technology (IRJET) e-ISSN: 2395 -0056, Volume: 03, Issue: 05, May-2016, pp 2100-2110.

[6] Salonee Mishra and Binod Kumar Pattanayak , "POWER AWARE ROUTING IN MOBILE AD HOC NETWORKS: A SURVEY", ARPN Journal of Engineering and Applied Sciences, ISSN 1819-6608, VOL. 8, NO. 3, MARCH 2013, pp 173-189. 
[7] Sathya.E and Rajpriya.G, "Power Aware Routing for Path Selection with Minimum Traffic in Mobile Adhoc Network", International Journal of Engineering Research and General Science, ISSN 2091-2730, Volume 2, Issue 6, October-November, 2014, pp 430-437.

[8] B. Karthikeyan and Dr.S.Hari Ganesh, "Encrypt Security Improved Ad Hoc On Demand Distance Vector Routing Protocol (En-SIm AODV)", ARPN Journal of Engineering and Applied Sciences (ISSN: 1819-6608), Vol. 11, No. 2, January 2016,pp. 1092-1096.

[9] B. Karthikeyan,Dr.S.Hari Ganesh and Dr. JG.R. Sathiaseelan, " Optimal Time Bound Ad-Hoc On- demand Distance Vector Routing Protocol (OpTiBAODV)", International Journal of Computer Applications (ISSN:0975 - 8887), Vol. 140, No.6, April 2016,pp 7-11.

[10] B. Karthikeyan, Dr.S.Hari Ganesh and Dr. JG.R. Sathiaseelan, "High Level Security with Optimal Time Bound Ad-Hoc On-demand Distance Vector Routing Protocol (HiLeSec-OpTiB AODV)",International Journal of Computer Science Engineering(E-ISSN: 2347-2693),Vol. 4, No. 4, April 2016, pp.156-164. 